\title{
Positivismo y Teoría Crítica: Desafíos Epistemológicos a Considerar en la Psicología Experimental
}

\section{Positivism and Critical Theory: Epistemological Challenges in Experimental Psychology}

\author{
Yasna Valenzuela Román' \\ Universidad Santo Tomás de Chile
}

(Recepción: Agosto 2005 - Aceptación: Noviembre 2005)

\begin{abstract}
La psicología experimental se enfrenta hoy a un gran desafio: debe responder a una serie de transformaciones provenientes tanto de las crisis de paradigmas como de las mudanzas tecnológicas, sociales, económicas, políticas, culturales que actualmente se evidencian en todo el mundo. Estos cambios afectan profundamente al sujeto psicológico y a la forma en que la psicología da cuenta de él. La premisa central de este artículo busca tanto exponer como proponer un cuestionamiento epistemológico a considerar para responder al desafío planteado. Palabras clave: Epistemología, teoría psicológica, positivismo
\end{abstract}

Experimental psychology is facing an enormous challenge today: It must respond to a series of transformations arising not only from paradigm crises but also from technological, social, economic, political, and cultural changes that are taking place around the world. These changes deeply affect the psychological subject and the way in which psychology perceives him or her. The main premise of this article seeks to open up and to propose an epistemological discussion to consider how to respond to this challenge.

Key words: Epistemology, psychological theory, positivism

Desde el texto de Horkheimer de 1937, "Teoría Tradicional y Teoría Crítica"2, hasta la disputa del positivismo en la sociología alemana ${ }^{3}$ en la década de los setenta, se expusieron una serie de debates que involucran problemas a considerar para los distintos enfoques de conocimiento. Estas discusiones han repercutido fuertemente en las últimas dos décadas. El trabajo que aquí se propone es una revisión reconstructiva de algunos tópicos de esas discusiones para considerarlas como retos epistemológicos en la psicología experimental. Lo que se busca, por tanto, no es el reemplazo de una perspectiva epistemológica por otra, sino poner en relación a la psicología experimental con estos problemas, ya que en ellos están involucrados los modos necesarios para dar cuenta de los cambios que el sujeto psicológico ha tenido en estas últimas décadas y las adecuaciones que precisa el régimen de la miradd de la psicolo-

' Psicóloga, Universidad de Chile. Magíster en Psicología, Mención Social y de la Personalidad, Universidade Federal do Rio de Janeiro. PhD en Filosofia, mención Epistemología de las Ciencias Sociales, Universidad de Chile. PhD(c) en Psicología, Universidad de Chile.

2 HORKHEIMER, Max. "TEORIA TRADICIONAL E TEORÍA CRÍTICA”. Edição Abril S. A. Cultural, Colección Os Pensadores. São Paulo, 1983. Págs. 117 y ss.

3 ADORNO, Theodor W. y otros. "LA DISPUTA DEL POSITIVISMO EN LA SOCIOLOGÍA ALEMANA". Editorial Grijalbo. Barcelona, 1973.

4 FOUCAULT, Michel. "EL NACIMIENTO DE LA CLÍNICA”. Editorial Siglo XXI. México, 1966, Pág. 5. gía experimental para adentrarse en sus contradicciones. El sistema de mirada es una clave que busca exponer las categorías conceptuales desde donde la psicología nombra sus objetos/ sujetos de estudio. Esto permite dilucidar en cada corriente psicológica y en sus propias rupturas el paso de lo precategorial a lo categorial.

"Para comprender cuándo se ha producido una mutación en un discurso, es menester interrogar algo más que a los contenidos temáticos o las modalidades lógicas, y recurrir a esa región en que palabras y cosas no están aún separadas"s. Esta zona se encuentra al nivel del lenguaje, en la manera de ver y de decir, en la distribución originaria de lo visible y lo invisible, en la medida en que ésto se encuentra íntimamente relacionado con lo que se dice y lo que se calla. Recién desde allí aparecerá la forma en que la psicología experimental mira a su sujeto de observación. Es entonces cuando se podrá apreciar en su propia luz la forma de ver dispuesta según estos códigos frente a un fenómeno determinado ${ }^{6}$.

Esta clave no solamente es importante para el análisis de determinados fenómenos, sino que es una de las llaves que posibilita la innovación

5 FOUCAULT, Michel. "EL NACIMIENTO DE LA CLÍNICA”. Editorial Siglo XXI. México, 1966. Pág. 4.

6 Esta idea se encuentra desarrollada en sí misma desde diferentes posicionamientos, es decir, hay formas muy distintas de ver el ver: Es diverso el "concreto pensado" de Marx al "traer todo un mundo en la mano" de Maturana. 
en las disciplinas en tanto permite ver lo que había permanecido en el umbral de lo visible y de lo enunciable. "La relación de lo visible con lo invisible, necesaria a todo saber concreto, ha cambiado de estructura y hace aparecer bajo la mirada y el lenguaje lo que estaba más acá y mas allá de su dominio. Entre las palabras y las cosas, se ha trabado una nueva alianza, que hace ver y decir, lo que en algunos discursos aparece casi como un regreso a una mirada al fin matinal"?.

El régimen de la mirada ha cambiado sustantivamente en la historia: para Descartes y Malebranche, ver era percibir, era hacer transparente para el ejercicio del espíritu: la luz anterior a toda mirada, el elemento de lo ideal, donde las cosas eran adecuadas a su esencia ${ }^{8}$.

A fines del siglo XVIII, ver consiste en dejar a la experiencia adentrarse en la densidad de las cosas encerradas en ellas mismas, ya que tienen poderes de verdad que no toman de la luz, sino de la lentitud de la mirada que las recorre?

Consecuentemente, el régimen de la mirada es fundador del sujeto en su calidad irreductible. En lo no-hablado, dirá Foucault, "duerme la palabra". De este modo, lo pensado cuenta tanto como lo no-pensado, ya que abre a la posibilidad de pensar de nuevo ${ }^{10}$. Esta categoría se vuelve relevante a la hora de analizar los diferentes regímenes de mirada que la psicología ha proyectado, porque posibilita estudiar sus fundamentos y, desde ellos, abrirse al espacio desafiante de lo no-pensado.

Consecuentemente, el trabajo se estructura de la siguiente forma:

7 FOUCAULT, Michel. "EL NACIMIENTO DE LA CLÍNICA". Editorial Siglo XXI. México, 1966. Pág. 5.

8 "La fórmula para alcanzar la esencia era a través de la geometría de los cuerpos; llegado a su perfección, el acto de ver se resolvía en la figura sin curva ni duración de la luz". FOUCAULT, Michel. "EL NACIMIENTO DE LA CLÍNICA". Editorial Siglo XXI. México, 1966. Pág. 7.

9 "La permanencia de la verdad es el núcleo sombrío de las cosas está paradójicamente ligada a este poder soberano de la mirada empírica que hace de su noche, dia. Toda la luz pasa del lado de la débil antorcha del ojo que da vuelta alrededor y dice, en este camino, su lugar y su forma". FOUCAULT, Michel. "EL NACIMIENTO DE LA CLÍNICA". Editorial Siglo XXI. México, 1966. Pág. 7.

${ }^{10}$ Esta es la puesta en acción de esa antigua categoría hegeliana donde conocer es diferenciar teniendo como horizonte que el no-ser forma parte del ser. HEGEL, G. W. F. "FENOMENOLOGÍA DEL ESPÍRITU". Editorial Fondo de Cultura Económica. México, 1966. Pág. 181.
I. Discusión de algunos supuestos epistemológicos en el positivismo y sus críticas realizadas tanto en el 37' como en los sesenta. Esto permitirá localizar puntos de recurrencia y no asumir supuestos que tuvieron una validez circunscrita históricamente.

II. Análisis de los conceptos de racionalidad, verdad y verificación, que sumados a los descritos en el punto I forman la base epistemológica de discusión para la psicología experimental.

III. Relación de esos aspectos con algunas dimensiones de la psicología experimental, especialmente desde la perspectiva de los impactos en el sujeto psicológico a partir de las transformaciones tecnológicas, denominada relación sujeto/máquina ${ }^{11}$. Se trata, por tanto, de mostrar cómo aun en el avance de las ciencias cognitivas persiste la deuda de la pregunta por el sujeto, ya que si bien éstas incorporan el concepto de mente en sus análisis, los componentes históricos permanecen todavía fuera de su universo interpretativo.

\section{Disputas del positivismo: Debates del 37', del 61' y del 64'}

"Si en el 37 Horkheimer señaló seminalmente las distinciones entre teoría tradicional y teoría crítica, la década de los sesenta nos deparó la polémica sobre el positivismo en la confrontación Popper-Adorno, continuada en los debates entre Albert y Habermas. Estas discusiones nos colocan frente a interrogantes epistemológicas centrales en el debate contemporáneo y en los tiempos de crítica a la modernidad"12.

El horizonte que nos propone lo anterior será reseñado en algunos de los aspectos sustantivos que fueron marcando el eje y la evolución de las discusiones.

\section{Max Horkheimer: La Crítica a la Teoría Tradicional}

Aquí no se intenta reproducir todos los argumentos y la relación entre teoría tradicional y teoria crítica que Horkheimer coloca en su texto, sino que en virtud del objetivo planteado

\footnotetext{
"Se ha seleccionado esta relación por constituir la categoría central de mi tesis a desarrollar en el magíster.

12 PICÓ, Josep. "MODERNIDAD Y POSTMODERNIDAD”. Editorial Alianza. Madrid, 1992. Pág. 13.
} 
se esbozará un eje referencial de la crítica de este autor a la teoría tradicional.

La primera impugnación de Horkheimer es sobre la concepción de teoría. Para él, en la teoría tradicional la teoría es "aquel conjunto de proposiciones relacionadas unas a otras acerca de un campo de objetos de las cuales pueden deducirse las restantes proposiciones"13. De este modo, subyace la siguiente relación: cuanto menor fuera el número de los principios primeros en comparación con sus conclusiones, más perfecta es la teoría. De allí emergen claramente las proposiciones de validez en la teoría tradicional que se traducen en el grado de concordancia entre las proposiciones deducidas y los hechos ocurridos ${ }^{14}$.

De esta forma, la teoría siempre será testeada desde los hechos. De allí que, en lo que concierne a los datos, la teoría permanecerá siempre hipotética. Consecuentemente, "la teoría se vuelve el saber acumulado de tal forma que permita ser utilizado en la caracterización de los datos, llevada a cabo en la forma más minuciosa posible" ${ }^{15}$. Por tanto, el concepto de teoría es de cierta forma autonomizado del contexto societal, en cuanto busca sus fundamentos a partir de una forma esencial e íntima del conocimiento, transformándose así, para Horkheimer, en una categoría cosificada. Para el autor, la teoría tradicional tiende a olvidar que los datos que se nos ofrecen son preformados de modo duplo: "por el carácter histórico del objeto percibido y por el carácter histórico del órgano perceptivo"16.

Lo anterior es crucial en todo tipo de concepción epistemológica que sustente la existencia, tal como el positivismo lo hace, de una realidad externa y cognoscible. Horkheimer apunta al develamiento del carácter no-natural de objeto y órgano, ya que ambos son formados por la actividad humana. De este mismo aspec-

${ }^{13}$ HORKHEIMER, Max. "TEORÍA TRADICIONAL E TEORÍA CRÍTICA”. Edição Abril S. A. Cultural, Colección Os Pensadores. São Paulo, 1983. Pág. 117.

14 "La validez real de la teoría reside en la concordancia entre proposiciones deducidas y hechos ocurridos, o lo que es lo mismo, entre teoría y empiria". HORKHEIMER, Max. "TEORÍA TRADICIONAL E TEORÍA CRÍTICA". Edição Abril S. A. Cultural, Colección Os Pensadores. São Paulo, 1983. Pág. 117.

15 HORKHEIMER, Max. "TEORÍA TRADICIONAL E TEORÍA CRÍTICA”. Edição Abril S. A. Cultural, Colección Os Pensadores. São Paulo, 1983. Pág. 117.

16 HORKHEIMER, Max. "TEORÍA TRADICIONAL E TEORÍA CRÍTICA”. Edição Abril S. A. Cultural, Colección Os Pensadores. São Paulo, 1983. Pág. 125. to Horkheimer hará surgir una significativa distinción entre normas de observación variadas para la sociedad o para el individuo. Para él, existen ocasiones en que el individuo se puede autopercibir pasivo e indefenso en relación con los mecanismos sociales y económicos de transformación. Sin embargo, si contemplamos la sociedad no podemos pensar en sus mecanismos de estructuración dirigidos como una forma ciega. Esta contradicción se hace evidente, para él, en el "modo burgués de la economía, donde la sociedad aparece ciega y concreta y la actividad del individuo abstracta y conciente"17.

Por tanto, especialmente las ciencias sociales y aquellas que trabajan con el sujeto no pueden olvidar ni la doble determinación ni la distinción tensional entre individuo y sociedad. Así, aparece en su plena expresión el que algunas dimensiones de las estructuras científicas dependen de las situaciones y procesos sociales. Esto es importante de resaltar, porque la teoría tradicional opera, por lo general, clasificando los datos en sistemas conceptuales que simplifican o eliminan las contradicciones. Para Horkheimer, esto también tiene una explicación cultural, en el sentido de que el desarrollo de las ciencias aparece desligado de esas luchas y por tanto "no se emplea tanta energía en desarrollar la capacidad de pensar contradicciones y relaciones complejas como la empleada en encontrar soluciones funcionales según el campo específico de aplicación"18.

Si la lógica anterior impregna el quehacer científico, las categorias de mejor, útil, conveniente, productivo, valioso, tal como son aceptadas por el orden social vigente, se vuelven fuera de sospecha y, por tanto, se ven como premisas extracientíficas que no requieren atención crítica. De esa forma, "el carácter discrepante y escindido del todo social, en su figura actual, no tiene camino para volverse una contradicción conciente"19. El riesgo de lo anterior es que al seguir la lógica expuesta la teoría tradicional no tiene cómo colocarse "contra el presente cuando

${ }^{17}$ HORKHEIMER, Max. "TEORÍA TRADICIONAL E TEORÍA CRÍTICA”. Edição Abril S. A. Cultural, Colección Os Pensadores. São Paulo, 1983. Pág. 125.

${ }^{18}$ HORKHEIMER, Max. "TEORÍA TRADICIONAL E TEORÍA CRÍTICA". Edição Abril S. A. Cultural, Colección Os Pensadores. São Paulo, 1983. Pág. 128.

19 HORKHEIMER, Max. "TEORÍA TRADICIONAL E TEORÍA CRÍTICA”. Edição Abril S. A. Cultural, Colección Os Pensadores. São Paulo, 1983. Pág. 130. 
el presente es miseria"20 . Así, Horkheimer busca interpelar a la teoría tradicional, haciendo notar que no es el pensamiento el que introduce la necesidad de los cambios sino que es el grado de injusticia el que impulsa a nivel del pensamiento conceptual la urgencia de la superación de las contradicciones.

\section{Las Disputas del Positivismo en la Década de los 60'}

Nuevamente en este punto la hondura y riqueza de los debates sostenidos por cuatro autores como Popper, Adorno, Albert y Habermas desbordan el horizonte de posibilidad de este trabajo. Por tanto, este aspecto se enmarcará siguiendo algunos de los tópicos básicos de discusión, usando para ello, sobre todo, el tratamiento relatorio que Habermas pone en su síntesis de las discusiones tanto en: "apéndice a una controversia de teoría analítica de la ciencia y dialéctica" como en "una polémica: contra un racionalismo disminuido en términos positivistas"21. Se ha optado por esta vía ya que lo que se busca exponer más que el contenido y límites de la dialéctica son los límites y críticas hacia el positivismo tanto clásico como en su evolución al racionalismo crítico.

Una primera y nuclear distinción es la que Adorno hace en relación con el concepto de totalidad. Para él, "la totalidad social no lleva ninguna vida propia por encima de lo que comprende, de aquello en que consiste. Se produce y reproduce a través de sus momentos particulares. $\mathrm{Ni}$ el todo puede ser aislado de la vida, de la cooperación y del antagonismo de sus elementos, ni tampoco puede entenderse el funcionamiento de ningún elemento sin tener presente el todo, que tiene su esencia en el movimiento de lo particular. Sistema y particularidad son recíprocos y sólo pueden conocerse en su reciprocidad"22.

${ }^{20}$ HORKHEIMER, Max. "TEORÍA TRADICIONAL E TEORÍA CRÍTICA”. Edição Abril S. A. Cultural, Colección Os Pensadores. São Paulo, 1983. Pág. 139.

21 Ambos artículos están contenidos tanto en el texto de ADORNO, Theodor W. y otros. "LA DISPUTA DEL POSITIVISMO EN LA SOCIOLOGÍA ALEMANA". Editorial Grijalbo. Barcelona, 1973; como en el del propio HABERMAS, Jürgen. "LA LÓGICADE LAS CIENCIAS SOCIALES”. Editorial Tecnos. Madrid, 1988

${ }^{22}$ ADORNO, Theodor W. y otros. "LA DISPUTA DEL POSITIVISMO EN LA SOCIOLOGÍA ALEMANA". Editorial Grijalbo. Barcelona, 1973. Pág. 123.
De esta manera, surge claramente la crítica a la relación establecida por el positivismo entre sistema y parte. Según Adorno, el positivismo deja de lado el que el proceso de investigación organizado por los sujetos pertenece, a través de los actos de conocimiento, al contexto objetivo que se busca conocer ${ }^{23}$.

Así, aparece una restricción en tanto "en el marco de una teoría estrictamente experimental el concepto de sistema no puede tener otro cometido que designar de modo formal el plexo interdependiente de funciones que a su vez se interpenetran como relaciones entre variables del comportamiento social"24. Dicho de otro modo, mediante esta lógica el concepto mismo de sistema permanece tan externo al ámbito analizado de la experiencia como las proposiciones teóricas que lo explicitan. Es decir, los preceptos de la metodología positivista "sólo contienen, junto a reglas de lógica formal para la estructuración de un plexo deductivo de proposiciones hipotéticas, la exigencia de elegir supuestos básicos simplificados que permitan la deducción de hipótesis legaliformes que sean empíricamente contrastables" 25

Adorno concluye de lo anterior que la ciencia social sólo puede liberarse en la medida en que entienda la red de la vida social como una totalidad que determina incluso a la investigación misma. Con ello la ciencia social pierde su presunta libertad en la elección de categorías y modelos, por cuanto "ahora sabe que no dispone de datos no cualificados, sino únicamente de datos que vienen estructurados por el plexo de la totalidad social"26.

Por otra parte, Adorno impugna la relación entre teoría y objeto, es decir, los términos más amplios de teoría y experiencia. Para él, los procedimientos empírico-analíticos sólo consienten un tipo de experiencia que ellos mismos definen. "Únicamente la observación controlada en un campo aislado y bajo circunstancias reconocibles que pueda ser organizada por su-

${ }^{23}$ ADORNO, Theodor W. y otros. "LA DISPUTA DEL PO SITIVISMO EN LA SOCIOLOGÍA ALEMANA". Editorial Grijalbo. Barcelona, 1973. Pág. 125.

${ }^{24}$ HABERMAS, Jürgen. "LALÓGICADE LAS CIENCIAS SOCIALES”. Editorial Tecnos. Madrid, 1988. Pág. 22.

${ }^{25}$ HABERMAS, Jürgen. "LALÓGICADE LAS CIENCIAS SOCIALES”. Editorial Tecnos. Madrid, 1988. Pág. 22.

${ }^{26}$ ADORNO, Theodor W. y otros. "LA DISPUTA DEL POSITIVISMO EN LA SOCIOLOGÍA ALEMANA". Editorial Grijalbo. Barcelona, 1973. Pág. 132. 
jetos intercambiables a voluntad, parece permitir juicios de percepción intersubjetivamente válidos"27. Estos juicios representan la base de experiencia en que descansan las teorías si las hipótesis obtenidas deductivamente son lógicamente correctas y empíricamente atinadas. De esta forma las ciencias experimentales, en sentido estricto, insisten en que toda proposición susceptible de discutirse pueda ser controlada "a lo menos indirectamente, por medio de esa experiencia tan estrechamente canalizada" 28 .

A estas críticas de Adorno, Habermas va a sumar sus apreciaciones sobre el papel de los enunciados metodológicos y lo que él denominará la escisión entre razón y decisión. Es interesante hacer notar que el propio Habermas sostiene que eligió para la discusión la teoría de Popper, "porque Popper ya da un paso en dirección a mis objeciones contra el positivismo"29. De esta forma, para Habermas, Popper ocupa una posición peculiar: por una parte es un representativo defensor de la teoría analítica de la ciencia y por otra es un encarnizado crítico de los presupuestos empiristas del nuevo positivismo. Así, es la propia crítica de Popper la que inicia una etapa de auto-reflexión en este enfoque epistemológico. Sobre ella, Habermas apuntará a los límites que este nuevo tipo de positivismo mantiene.

Su primera crítica se orienta a los criterios de validez empírica de los enunciados, en el sentido de que el positivismo supone como único legítimo un procedimiento de comprobación que es sólo "uno entre muchos" ${ }^{30}$. Sin embargo, concordará con Popper al admitir que los datos experimentales son "interpretaciones en el marco de teorías previas, y por tanto, también comparten el carácter hipotético de aquellas" ${ }^{\text {31 }}$, sólo que Habermas discrepará de la distinción entre conjeturas y refutaciones que Popper efectúa. Para Habermas "todas las fuentes del conocimiento son fuentes siempre impuras, donde el camino a los orígenes nos está interceptado. De

27 ADORNO, Theodor W. y otros. "LADISPUTA DEL POSITIVISMO EN LA SOCIOLOGÍA ALEMANA". Editorial Grijalbo. Barcelona, 1973. Pág. 137.

${ }^{28}$ HABERMAS, Jürgen. "LALÓGICADE LAS CIENCIAS SOCIALES”. Editorial Tecnos. Madrid, 1988. Pág. 24.

29 HABERMAS, Jürgen. "LA LÓGICADE LAS CIENCIAS SOCIALES”. Editorial Tecnos. Madrid, 1988. Pág. 46.

${ }^{30}$ HABERMAS, Jürgen. "LA LÓGICA DE LAS CIENCIAS SOCIALES”. Editorial Tecnos. Madrid, 1988. Pág. 47.

31 POPPER, Karl. "EL DESARROLLO DEL CONOCIMIENTO CIENTÍFICO. CONJETURAS YREFUTACIONES”. Editorial Paidós. Buenos Aires, 1964. Págs. 23 y 387. ahí que la cuestión del origen del conocimiento no puede mediatizar por igual todos los orígenes de la teoría, a saber: la observación, el pensamiento y la tradición frente al método de la falsación, que es el único que para Popper debe medir la validez empírica de las teorías" ${ }^{32}$.

De esta forma, Habermas impugna a Popper el no develar que el método de la falsación en realidad corresponde y se justifica recurriendo, al menos, a una de las fuentes del saber que es la tradición y que paradójicamente Popper denomina tradición crítica. Con ello queda de manifiesto que la tradición es la variable independiente de la que en último término dependen tanto el pensamiento y la observación como los procedimientos de observación que se forman por combinación de ellos. "Popper pone con demasiada ligereza su fe en la autonomía de la experiencia organizada en el procedimiento de falsación, cree poder deshacerse así de la cuestión de los estándares de esa organización porque, pese a todas sus críticas, sigue compartiendo todavía un prejuicio positivista de profundo arraigo: el suponer la independencia epistemológica de los hechos respecto a las teorías cuya función sería aprehender descriptivamente estos hechos y las relaciones entre ellos" ${ }^{\text {"33 }}$. De esta forma, para Popper todavía los test contrastan teorías con hechos independientes, evidenciando lo que para Habermas constituye "el punto angular de la problemática positivista que residualmente queda aún en Popper"34.

\section{Racionalidad, Verdad y Verificación: Supuestos Epistemológicos Centrales en una Perspectiva Positivista}

\section{Racionalidad}

Una de las premisas centrales en Popper está configurada por el supuesto de conocimiento racional. El concepto de racionalidad es fundamental porque implica tocar el núcleo de la argumentación popperiana, ya que la forma de establecer un conocimiento científico válido descansa en la rigurosidad de la lógica. Esto tiene una singular

${ }^{32}$ HABERMAS, Jürgen. "LALÓGICA DE LAS CIENCIAS SOCIALES”. Editorial Tecnos. Madrid, 1988. Pág. 49.

33 HABERMAS, Jürgen. "LA LÓGICA DE LAS CIENCIAS SOCLALES”. Editorial Tecnos. Madrid, 1988. Pág. 49.

34 HABERMAS, Jürgen. "LALÓGICADE LAS CIENCIAS SOCIALES”. Editorial Tecnos. Madrid, 1988. Pág. 50. 
importancia para la psicología, ya que el modelo de investigación positivista la ha influído notablemente. Este concepto servirá además para poder plantear algunas interrogantes en relación con las formas de investigación y acceso a la realidad social que se busca conocer.

Popper acepta componentes no racionales dentro de lo que él denomina "conjeturas" del desarrollo científico, pero no así dentro del terreno de la refutación ${ }^{35}$.

En el proceso que va desde la selección del problema (donde afirma los límites de la observación posible), la formulación de conjeturas, las proposiciones que se contrastan empíricamente, los test de falsación y el resultado de falsasión o apoyo (con su consiguiente elección entre explicaciones alternativas) existe un supuesto, una división artificial. Y es que Popper, al suponer que los elementos no racionales intervienen sólo en el plano de las conjeturas, está:

\subsection{Separando el conocimiento de los intereses.}

A esto Habermas lo llamará el quiebre insostenible, ya que los intereses están siempre presentes en el quehacer científico. El concepto de interés como guía del conocimiento queda perdido en la relación entre conocimiento e interés. La presentación de ideas arbitrariamente separadas sirve a menudo para enmascarar con pretextos de legitimación los motivos reales de las acciones. No todo se lleva a cabo como Popper lo afirma, dentro de un marco estrictamente racional. "A lo que en este plano denominamos racionalización, en el plano de la acción colectiva lo denominamos ideología. Pero esto es sólo un lado de la cuestión, ya que por otra parte, por tener que ganar primeramente la objetividad de sus enunciados contra la presión y la seducción de intereses particulares, la ciencia se engaña sobre los intereses fundamentales a los que agradece no sólo su impulso, sino también las condiciones de posible objetividad" 36 .

Así Popper se centra en un tipo de conocimiento, al que Weber denominaría como pro-

35 Acerca de lo que el autor entiende por cada uno de estos conceptos, se remite al capítulo 1 de: POPPER, Karl. "EL DESARROLLO DEL CONOCIMIENTO CIENTÍFICO. CONJETURAS Y REFUTACIONES". Editorial Paidós. Buenos Aires, 1964. Págs. 43 a 79.

${ }^{36}$ HABERMAS, Jürgen. "CONOCIMIENTO E INTERÉS”. Editorial Tecnos. Madrid, segunda edición 1983. Págs. 173 y ss. veniente de una razón instrumental de medios a fines. No integra al desarrollo del conocimiento de la ciencia otros dos necesarios tipos de conocer, como son el práctico vivencial y el emancipador.

1.2 Popper coloca su acento en el plano de los enunciados, no discute el lenguaje y modelo teórico que existen en ellos. Al excluir una discusión acerca de los objetivos y valores a los que adhiere la ciencia, esta queda entregada a un nivel de decisionismo. "Guiada por la actitud objetivista de la teoría configuradora de hechos, la dimensión en la cual los sujetos activos pueden llegar a un entendimiento racional y mutuo sobre objetivos y fines, es entregada a la oscuridad de la mera decisión entre el sistema de acciones cosificadas de valor y el poder irracional de la creencia"37.

Es de ese modo como la nítida frontera trazada por Popper entre conocimiento y valoración representa, en realidad, no tanto un resultado (aunque él llega a este límite realizando un exhaustivo análisis de autores, por ejemplo en la miseria del historicismo), como un problema. Detrás de su pretensión de entregar a la ciencia racional el requisito más importante para lo que se considera el desarrollo científico, se encuentra de nuevo el plano de las decisiones valóricas, que quedan entregadas a principios de una elección irracional. Popper mismo sostiene que "no me es posible racionalmente obligar a nadie a que apoye sus presunciones con argumentos y experiencias. Igualmente, tampoco yo puedo, con ayuda de argumentos y experiencias, justificar concluyentemente mi resolución de adoptar, digamos, una conducta determinada. En este sentido mi adopción de una actitud racionalista requiere también una decisión al respecto. También aquí el problema reside no en la elección entre razón y fe, sino únicamente en la elección entre dos tipos de fe" ${ }^{\prime 38}$.

1.3 El concepto popperiano de racionalidad, reducido en la línea del positivismo, exige tan sólo, en primera instancia, que el mayor número posible de individuos adopte una actitud racionalista. Tal actitud, ya determine la

37 HABERMAS, Jürgen. "TEORÍA Y PRAXIS".Editorial Tecnos. Madrid, 1987. Págs. 231 y ss.

38 POPPER, Karl. "CONOCIMIENTO OBJETIVO: UN ENFOQUE EVOLUCIONISTA”. Editorial Tecnos. Madrid, 1986. Pág 193. 
conducta en el proceso de investigación o en la praxis social, se orienta por las reglas de la metodología científica. Acepta las normas usuales de la discusión científica, se muestra informada del dualismo entre hechos y decisiones y conoce los límites del conocimiento intersubjetivamente válido. Por ello se opone al dogmatismo, tal como los positivistas lógicos lo entienden, $\mathrm{y}$ al emitir su juicio acerca de sistemas de valores y normas sociales en general, "se obliga a la observancia de principios críticos que fijan la relación entre teoría y praxis" 39 .

1.4 Para Popper, las teorías son enunciados universales y, como toda representación, sistemas de signos o símbolos. Pero, asumiendo la perspectiva que sostiene Foucault, se podría afirmar que la práctica es un conjunto de conexiones de un punto teórico con otro y la teoría un empalme de una práctica con otra. Así el teórico ha dejado de ser un sujeto que se debe situar "un poco en avance o un poco al margen para decir la muda verdad de todos" sino aquél que "enfrenta las formas de poder allí donde éste es a la vez objeto e instrumento: en el orden del saber, de la verdad, de la conciencia, del discurso" ${ }^{40}$. De esta forma la teoría es una práctica, $\mathrm{y}$ funciona exactamente como una caja de herramientas. Como ya escribía Proust, "tratad mi libro como un par de lentes dirigidos al exterior $y$, bien, si no os sirven, tomad otros, encontrad vosotros mismos vuestro aparato que es necesariamente un aparato de combate" 41 .

1.5 La idea anteriormente expuesta dice relación con la noción de paradigma de Kuhn y algunos problemas en ella ${ }^{42}$ que están referidos al papel de la ideología ${ }^{43}$ en el proceso de constitución del saber. Kuhn sólo la considera

39 HABERMAS, Jürgen. "DOGMATISMO, RAZÓN Y DECISIÓN". En: "TEORÍA Y PRAXIS". Editorial Tecnos. Madrid, 1987. Pág 310.

${ }^{40}$ FOUCAULT, Michel. "LA ARQUEOLOGÍA DEL SABER”. Editorial Siglo XXI. México, 1979. Pág. 186.

${ }^{41}$ PROUST, Marcel. "EN BUSCA DEL TIEMPO PERDIDO". Ediciones Alianza. Madrid, 1980.

${ }^{42}$ El mismo Kuhn propone una discusión sobre este aspecto en su texto "LA TENSIÓN ESENCIAL". Editorial Fondo de Cultura Económica. México, 1987. Págs 248 a 263.

${ }^{43}$ Usando el concepto que Horkheimer propone "every human way of acting wich hides the true nature of society, built as it is on contrarieties, is ideological...". HORKHEIMER, Max. "CRÍTICAL THEORY". The Seabury Press. New York, 1972. Pag. 7. como parte de la ciencia normal y, en consecuencia, como elemento que aporta al desarrollo de un nuevo paradigma. Pero no se discute cómo la ideología es parte constitutiva de cualquier tipo de proceso de conocimiento, aun del científico que genera saber.

La separación de teoría y praxis no es considerada por Kuhn en la estructura explicativa sobre el desarrollo de la ciencia, al no considerar la ideología en el proceso de constitución del saber científico. Esto produce no sólo rechazo sino aceptación del uso de la noción de paradigma. El proceso de legitimación del desarrollo del acontecer científico está atravesado por el concepto khuniano de paradigma. Se trata de ir más allá de lo cualitativo o cuantitativo. La necesidad de dar legitimidad a la investigación en ciencias sociales a través de conceptualizaciones externas, sigue oscureciendo una discusión aclaratoria centrada en los modos que asume la relación sujeto objeto en el conocimiento del hombre en sus relaciones con la realidad y con los otros, considerando en ello el interés y la necesidad que subyace a todo conocer. Es decir, reconociendo transparentemente el papel de la ideología en este proceso. Además, la discusión ha llevado a asumir posiciones radicales en cuanto a la relevancia asignada a cada uno de los elementos que articulan la relación de conocimiento. Uno de los polos, donde prevalece el objeto, desconociendo la historicidad de su constitución e ignorando al sujeto, es el núcleo más radical del positivismo. Acá la palabra clave es método, o más contemporáneamente paradigma, cuya presencia o ausencia, legitima o ilegaliza la condición científica de las investigaciones. La otra sobredimensiona al sujeto. Su filiación reclama de los enunciados de Husserl y Schutz, y la palabra clave es intersubjetividad. Pero esta intersubjetividad aparece descontextualizada de las condiciones de la formación histórico-social donde se concretiza. Ambas posturas comparten la inexistencia de una conceptualización acerca de la relación sujeto/objeto como totalidad.

1.6 Por último, lo anterior evidencia con toda su fuerza los agudos problemas de mediación que existen hoy. Es decir, el que la cultura de expertos, entre ellas la psicología, se ha encapsulado de tal forma que con las pala- 
bras metodológicas que usa para abordar la realidad se ha vuelto incapaz de nombrar algunos de los procesos contradictorios que se producen en ella. Un camino metodológico que sólo pone énfasis en el despliege de los elementos racionales deja fuera -usando palabras de Foucault-las herramientas conceptuales que permitan "la insurrección de los saberes sometidos desde sus prácticas" ${ }^{\text {"4 }}$. La insurrección que Foucault propone debe entenderse como la rebelión de una serie de saberes calificados como incompetentes o insuficientemente elaborados para el nivel de la cientificidad racional exigida. No significa traducirlos, o encerrarlos, sino recorrerlos, descubrirlos, acercarse a su sentido. No se trata de una rebelión contra (y solamente) los métodos de una ciencia sino, y sobre todo, contra los efectos del saber centralizador que ha sido legado al discurso científico organizado.

\section{Verdad y Verificación}

El planteamiento de Popper responde a una concepción moderna del acontecer científico. La "verdad" ya no tiene referencia a un pasado, o a las tradiciones o a Dios, no proviene de una revelación, sino que busca su propio camino dentro del conocimiento. Esta afirmación se encuentra en las bases constitutivas del pensamiento de la modernidad ${ }^{45}$. Dicho en palabras de Habermas, se han diferenciado drásticamente las esferas de lo cognitivo, lo ético y lo estético, por lo que lo verdadero ya no es lo bueno o lo bello. Cada uno se ha refugiado dentro de su propia lógica ${ }^{46}$. El criterio de verdad se encuentra inmerso dentro de la discusión sobre los fundamentos del conocimiento, ya que es central saber cómo se conoce para acceder a la verdad dentro de ese conocer. En Popper, el modelo del conocimiento científico con su lógica racional es el modelo más perfecto de conocimiento.

${ }^{44}$ FOUCAULT, Michel., "LA MICROFÍSICA DEL PODER” Editorial La Piqueta. Madrid, 1979. Pág. 128.

45 Como afirma Marcel Gauchet "La modernidad es, ante todo, un proceso de secularización: el lento paso del orden recibido al orden producido". GAUCHET, Marcel. "LE DÉSENCHANTEMENT DU MONDE". Editions Gallimard. París, 1985.

46 Para un despliege de estos conceptos se remite a: HABERMAS, Jürgen. "LA MODERNIDAD UN PROYECTO INCOMPLETO", en la compilación realizada por FOSTER, Hal. "LA POSMODERNIDAD". Editorial Kairós. Barcelona, 1986. Pág. 24.
El autor se distancia de los positivistas lógicos al construir su asimetría lógica entre verificación y falsedad. Esta consiste en sostener que aunque ningún número de observaciones nos permite alcanzar una proposición universal (por lo que la verificación no es posible), basta con una observación que señale lo contrario para concluir que la proposición es falsa. De este modo la única proposición que puede aspirar a la verdad es aquella que puede ser falseada ${ }^{47}$. Así, Popper construye un concepto de verdad que es siempre gradual, ya que el conocimiento científico nunca puede alcanzarla plenamente. Un requisito indispensable de la ciencia será, por tanto, su carácter provisional. La verdad pasa a ser, dentro de este planteamiento, algo semejante a un referente utópico, ya que no se alcanza jamás. Lo que sí hay son elementos para afirmar y discriminar, entre varias teorías, cuál de ellas está más cerca de esa verdad provisional.

Consecuentemente, la tarea de la ciencia no consiste ya en probar la verdad de algo o en comprobar sus planteamientos, sino en la capacidad para someterse a los procedimientos de refutación. El avance de la ciencia se produce entonces por el proceso de ensayo y error. $\mathrm{La}$ contrastación en Popper tiene como procedimientos básicos: verificación de la coherencia lógica del sistema teórico, revisión de formulaciones teóricas de acuerdo a si son empíricas o no, y una comparación de esta teoría con otras sobre el mismo tópico.

Ahora bien, al concebir la verdad como algo provisorio y entregar la verificación a la posibilidad de falsear, Popper amarra estas categorías relacionándolas e insertándolas drásticamente dentro de su lógica racional, en el interior de lo que él considera los requisitos para todo conocimiento científico. En este mismo sentido, los criterios de validez o de verdad se definen por procedimiento. Como sostiene el propio Popper, "es la forma de su desarrollo lo que hace a la ciencia racional"48. En este sentido, la comparación de dos teorías requiere el que ambas estén dentro de un mismo paradigma de investigación, luego es una comparación sólo dentro de aquellas contenidas en una misma matriz.

${ }^{47}$ Esta idea se encuentra profundizada en: ECHEVERRÍA, Rafael. "EL BUHO DE MINERVA". Ediciones PIIE. Santiago de Chile, 1988. Pág. 177.

48 POPPER, Karl. "EL DESARROLLO DEL CONOCIMIENTO CIENTÍFICO. CONJETURAS Y REFUTACIONES”. Editorial Paidós. Buenos Aires, 1964. Pág. 250. 
Con ello se da un acotamiento y se fija un límite importante a uno de los procedimientos de Popper en relación a la contrastación. Para el autor "todas las propiedades que requerimos para comparar y desear en una teoría equivalen a una sola cosa: al mayor grado de contenido empírico o de testabilidad"49.

Por otra parte, a la inversa de los autores empiristas que parten de lo empírico como un dato, haciendo de lo inductivo una premisa básica, Popper parte de un sistema hipotético deductivo donde se comienza a partir de la teoría y se realiza una explicación lógica pero que no es una explicación sobre causalidad. De este modo, al aproximar el concepto de teoría científica al formato hipotético deductivo, Popper no considera lo suficiente el que la sola descripción del mundo positivo y físico es ya problemática y que dentro de cada teoría existe un lenguaje y un modelo que constituyen una interrelación indisoluble con los enunciados.

$\mathrm{Al}$ contextualizar su requisito de falsear ${ }^{50} \mathrm{den}$ tro del marco de la lógica racionalista, Popper devela que, de concordar con él en este aspecto, se debe necesariamente compartir toda su estructuración. Así sucede lo que, expuesto en palabras de Foucault, es un principio de lectura de elección y exclusión, ya que "de todo lo que pasa no comprenderás más de lo que se ha convertido en inteligible porque ha sido ciudadosamente extraído y seleccionado para hacer ininteligible al resto. Bajo las especies de lo que se denomina la verdad, se trata siempre de conjurar lo que acontece: el suceso" ${ }^{51}$. De ese modo lo que conocemos por verdad, o los procedimientos para acceder a la verdad dentro de un conocimiento científico, pasa por una forma de imposición de cierto filtro de saber (que contiene un procedimiento de lógica racional) que se oculta bajo el aspecto universal y objetivo de este conocimiento.

Por otra parte, la verdad y su definición nunca están exentas de su relación con los mecanismos de poder. Es decir, cada sociedad ha tenido y presenta hoy su política general de la

49 POPPER, Karl. "EL DESARROLLO DEL CONOCIMIENTO CIENTÍFICO. CONJETURAS Y REFUTACIONES”. Editorial Paidós. Buenos Aires, 1964. Pág. 253.

${ }^{50}$ La riqueza de este concepto y la interpretación que Popper hace se encuentran ampliamente descritos en su cuarto capítulo de "LA LÓGICA DE LA INVESTIGACIÓN CIENTÍFICA". Editorial Tecnos. Madrid, 1985. Págs. 75 a 88.

${ }^{51}$ FOUCAULT, Michel. "LA MICROFÍSICA DEL PODER”. Editorial La Piqueta. Madrid, 1979. Pág. 33. verdad, los tipos de discurso que acoge y hace funcionar como verdaderos, los mecanismos e instancias que permiten distinguir los enunciados verdaderos de los falsos, las técnicas y procedimientos para obtenerlos. En nuestra sociedad estos criterios son inseparables del discurso científico y de las instituciones que lo producen. "Existe un combate por la verdad o al menos alrededor de la verdad, que es lo mismo que sostener que el debate se encuentra al nivel del conjunto de reglas sobre las cuales se discrimina lo verdadero de lo falso y se ligan a lo verdadero efectos políticos de poder"s2.

Así es como detrás del concepto de verdad encontramos su propia presuposición. La elección de determinados criterios para definir la verdad, sus procedimientos de realidad y racionalidad son la elección de un producto humano. Es un acto social y depende de la situación histórica. Usando las irreverentes y lúcidas palabras de Feyerabend "uno se decide en favor o en contra del estilo de pensamiento racional de la ciencia por algo tan irracional (aunque no tan inocente) como uno se decide por el punk rock o en contra de él, por lo demás con la diferencia de que la actual inserción social de las ciencias rodea a la decisión del primer caso con mucha más palabrería y también con mucho más ruido" 53 .

En el mismo Feyerabend se encuentra una inversión propuesta para descubrir mediante las artes el estado de la ciencia. "Si viviéramos en un tiempo en que se creyera ingenuamente en el poder curativo y en la objetividad de las artes, si no se separa arte y Estado, si las artes se sustituyeran con medios fiscales, si se las aprendiera en las escuelas como disciplinas obligatorias, mientras que las ciencias serían consideradas como colecciones de juguetes, de las que los jugadores una vez elegirían un juego y otra vez otro, entonces, como es natural, sería igualmente indicado recordar que las artes son ciencias. Pero, desgraciadamente no vivimos un tiempo así"s4.

De esta forma, Popper realiza un considerable esfuerzo al criticar algunas de las categorías centrales del positivismo clásico: su nexo con la empiria, sus procesos de verificación, la propia noción de teoría, la lógica de la investiga-

52 FOUCAULT, Michel. "LA MICROFÍSICA DEL PODER”. Editorial La Piqueta. Madrid, 1979. Pág. 188.

53 FEYERABEND, Paul. "ADIÓS A LA RAZÓN". Editorial Tecnos. Madrid, 1984. Pag. 189.

${ }^{54}$ FEYERABEND, Paul. "ADIÓS A LA RAZÓN". Editorial Tecnos. Madrid, 1984. Pag. 190. 
ción y los pasos a seguir. Sin embargo, la crítica a la noción de totalidad, a la relación del sistema y la parte, el carácter no natural tanto del objeto como del órgano perceptivo, la ilusión de neutralidad en las refutaciones, la separación de conocimiento e interés y el aislamiento de razón y decisión continúan como problemas a resolver en esta perspectiva de conocimiento. Habrá que analizar, por tanto, cuál es el impacto de estas nociones en la Psicología Experimental. Es decir, hasta qué punto ella ha logrado, en primer lugar, evolucionar asumiendo las propias críticas de Popper al positivismo clásico y, en segundo término, en qué medida ella considera alguno de los problemas posteriores que han sido enunciados por los debates epistemológicos hace ya más de treinta años.

\section{Desafios Epistemológicos en la} Psicología Experimental. Ejemplificación Vista en la Relación Sujeto/Máquina

Lo que este punto pretende abordar son algunas dimensiones de la psicología experimental vistas a través del ejemplo de los impactos en el sujeto psicológico a partir de las transformaciones tecnológicas, denominadas como relación sujeto/máquina.

La premisa central de mi tesis plantea que la relación sujeto/máquina se ha configurado como una totalidad histórica que reclama la interpretación psicológica, al constituirse en una de las dimensiones antropológicas centrales del sujeto contemporáneo.

Si consideramos que la psicología requiere, en su trabajo de construcción objetual, un análisis del sujeto situado ${ }^{55}$, enfrentado al entorno, entonces ella no puede prescindir de su nexo con uno de los ejes transformadores de las relaciones societales que más fuertemente impactan al sujeto y del que surgen, a su vez, otros tipos de sujeto.

En otras palabras, la psicología se ejerce históricamente en el interior de una antropología, la cual ostenta la doble condición de hallarse a la base tanto de las categorías de comprensión

${ }^{55}$ Se ha preferido la denominación sujeto porque éste no surge por un desarrollo natural preordenado y preinscrito sino que ocupa siempre un lugar simbólico. El individuo aparece como categoría biológica, como polo alternativo conceptual de la especie. Mientras que el sujeto, atravesado por el significante es una categoría cuyo correlato es el otro. BRAUNSTEIN, Néstor. "LA RE-FLEXIÓN DE LOS CONCEPTOS DE FREUD EN LA OBRA DE LACAN". Editorial Siglo XXI. México, 1987. Pág. 16. de mundo de los sujetos que analiza como de los que son analizados.

Lo anterior implica la posibilidad de concebir vínculos entre la psicología y la modernidad, entendida esta última como una de las concepciones que permiten explicar el proceso de diferenciación societal en su paso de un orden recibido a un orden producido $0^{56}$. Si el surgimiento de la psicología, inscrito en el primer momento de la modernidad, conllevó la estructuración fundante de las corrientes y enfoques clásicos de la disciplina, la psicología contemporánea, enfrentada hoy a la ruptura y aceleradas transformaciones de un segundo momento de la modernidad, debe repensarse en dicho vínculo si quiere ser una respuesta para los sujetos en estas nuevas condiciones. Consecuentemente, la relación sujeto/máquina es la forma de expresión de una época que constituye horizonte y desafio para la psicología.

Lo que se aborda a continuación son algunos de los problemas epistemológicos vistos desde la noción descrita en la evolución de la Psicología Conductual a la Psicología Cognitiva.

\section{Una Psicología sin Psiquis}

Los inicios del conductismo se podrían definir perfectamente con el concepto: "psicología sin psiquis" "Parece haber llegado el tiempo de que la psicología deba descartar toda referencia a la conciencia. Ya es hora de que no siga engañándose a sí misma, pensando que los estados mentales constituyen el objeto de sus observaciones"s8.

La orientación de Watson representa la tentativa de definir la tarea de la psicología transformándola en una ciencia natural. Su programa excluye el campo integral de la conciencia y arroja por la borda los supuestos neurológicos para circunsccribir el dominio de la antigua ciencia de la mente al estudio del comportamiento

56 GAUCHET, Marcel. "LA PRODUCCIÓN DEL ORDEN”. Ediciones la Piqueta. Madrid, 1990. Pág. 23.

57 Concepto aplicado por Desiderio Papp al surgimiento del conductismo. PAPP, Desiderio. "HISTORIA DE LA CIENCIA EN EL SIGLO XX”. Editorial Universitaria. Santiago de Chie, 1983. Pág. 349.

58 WATSON, J.B. "BEHAVIORISM". Chicago Press. Chicago, 1930. En: PHOENIX BOOKS, 1966. Pág. 2. 
observable ${ }^{59}$. Quedan proscritos conceptos como espíritu y mente, satisfacción o disgusto.

Watson estima que la caja de misterios del cerebro es inaccesible a una observación objetiva, por tanto, ésta se remite a la observación de comportamientos entre estímulo y respuesta. Asimismo, todo el comportamiento humano debía ser explicado por el mecanismo de comportamiento. Sustituye así el dualismo ontológico por un dualismo biológico social: el de organismo y medio. El régimen de la mirada en la psicología se devela como una perspectiva práctica que tiene la tarea de prever la respuesta conociendo el estímulo y predecir el estímulo conociendo la respuesta. Paradójicamente, esta psicología se basa en la idea de observar.

Como prueba de esterilidad de la psicología tradicional y como un estímulo a su concepción, Watson aprueba la floreciente situación en que se encuentran las ramas de la psicología que se han separado de la psicología de la conciencia y que constituyen la psicología aplicada (psicología experimental, test, psicología de la publicidad, del trabajo, industrial), cuyo carácter científico no le planteaba reparo.

De allí surge también la importancia de la psicología animal y de su postulado fundamental: el hombre no se distingue del animal más que por el grado de su complejidad, el mecanismo de base es el mismo, es decir, el arco reflejo, el dualismo estímulo-respuesta con sus correlatos de condicionamiento y aprendizaje.

Para Skinner, la orientación central estaba dada por la descripción de la conducta, colocando al organismo en condiciones experimentales exactamente determinadas. Esto implica la transformación de la psicología en una ciencia del comportamiento.

Evidentemente, y sin negar todos los logros históricos alcanzados por este enfoque, desde la perspectiva de la relación sujeto/máquina hay una imposibilidad. No hay sujeto en su sentido pleno sino simplemente un sujeto operante. Obviamente lo que se sabe de él, por tanto, son los efectos observables de su operar. Al dejar de lado todos los procesos mentales no cuantificables y el proceso de la caja negra, se coharta

59 "Un observador cínico estaría tentado a decir que la psicología, después de haber vendido su alma, exhaló luego su espíritu y ahora, en el momento de su fin prematuro, parece haber perdido su conciencia". BURT, Cyril. "BRITISH JOURNAL OF PSYCHOLOGY”. 1962. Pág. 229. toda posibilidad de interpretar una relación sujeto/máquina sino bajo la estructura de sentido que expone que el hombre puede ser concebido como una máquina, ajustándose en esto al pensamiento de La Mettrie ${ }^{60}$.

Una de las grandes críticas a estos planteamientos la sostendrá Piaget al afirmar que, por lo menos, Watson y el conductismo tendrían que reconocer que a medida que han avanzado los conocimientos en biología cerebral, no es posible seguir pensando que esa caja negra no tenga, al menos, neuronas pensantes.

\section{Influencia del Behaviorismo en el concepto de Neutralidad. Terapéutica en el Psicoanálisis}

"Hay una forma mental muy autóctona de concebir a los principios de neutralidad analítica que bajo el nombre de behaviorismo domina hasta tal punto la noción psicológica en Norteamérica que está claro que a estas alturas ha recubierto totalmente en el psicoanálisis la inspiración freudiana"61. Así da cuenta Lacan del problema que involucra considerar al concepto de neutralidad terapéutica positivistamente en el psicoanálisis $^{62}$. Incluso podemos encontrar ya en los escritos de Freud una advertencia clara al respecto $^{63}$.

${ }^{60}$ Sin lugar a duda, la expresión filosófica más radical del hombre-máquina la construyó Julien Offray de la Mettrie (1709-1751). Para La Mettrie el hombre tiene un fundamento material que permite concebirlo "como una máquina complicada", ya que las aptitudes espirituales del hombre son sólo funciones naturales e intrínsecas de la materia orgánica. Para él los movimientos instintivos, el que los párpados se cierren cuando los amenaza un golpe o que los poros de la piel se cierren en invierno por el frío o que el corazón se contraiga en el sueño no son sino evidencias de un funcionamiento maquinal. DE LA METTRIE, Julien. "DER MENSCH EINE MASCHINE". Biblioteca Filosófica. Tomo 68. Editorial Dürr. Leipzig. Pág. 50.

${ }^{61}$ LACAN, Jacques. "ESCRITOS". Editorial Siglo XXI. Buenos Aires, 1977. Pág. 235.

62 "Aparece de forma innegable que la concepción del psicoanálisis se ha inclinado allí hacia la adaptación del individuo a la circunstancia social, la búsqueda de los patterns de conducta y toda la objetivación implicada en la noción de human relationes". LACAN, Jacques. "ESCRITOS". Editorial Siglo XXI. Buenos Aires, 1977. Pág. 236.

${ }^{63}$ La interpretación psicoanalítica se compara a una traducción de una lengua a otra, a la solución de un juego de significaciones: "el sueño es un juego de significaciones, nuestros predecesores han cometido el error de querer interpretarlo como imágenes y acontecimientos, ligados a la noción de hechos. Esta es la razón por la cual les ha parecido absurdo y sin valor". FREUD, Sigmund. "LA INTERPRETACIÓN DE LOS SUEÑOS". Editorial Alianza. Madrid, 1983. Págs. 241 y 242. 
Es, por tanto, la estructura psíquica la que permite insertar los actos conscientes en el texto de los actos inconscientes. Así, el sentido de los hechos en psicoanálisis se diferencia de la idea positivista de hechos al modo de Durkheim ${ }^{64}$. La no consideración de estas distinciones ha posibilitado el surgimiento de una perspectiva de neutralidad terapéutica en el psicoanálisis que tiene entre otras expresiones las siguientes:

i. creer que se trabaja con enunciados observables y contrastados: "ya que son hechos perfectamente contrastables, el fracaso en nuestras predicciones puede suministrarnos información siempre y cuando no nos dejemos involucrar terapéuticamente y mantengamos nuestra neutralidad al respecto" ${ }^{65}$.

ii. pensar que el uso del computador implica un tipo de neutralidad más riguroso: "aún no tenemos experiencia suficiente, por lo menos transmisible, de análisis realizados con un mínimo de interferencia del terapeuta. Esto vendrá con el uso de computadoras automáticas que permitirán la casi total fiabilidad en el registro de hechos"66.

iii. dejar los procesos de codificación entregados a una máquina, como la ilusión de reemplazo de los mecanismos de subjetividad del terapeuta: "los procesos de codificación nos permitirán tener un set de códigos en los cuales insertar las nuevas sesiones y entregar resultados sin que éstos hayan pasado por el contagio del terapeuta"67.

Así, la neutralidad se entiende dentro del marco epistemológico del positivismo, que procura aislar razón de decisión técnica ${ }^{68}$, asume la realidad como un objeto externo y cognoscible, donde los pasos del método y la adecuación del sujeto al objeto son una garantía del logro de objetividad.

64 "Tratad a los hechos sociales como si fueran cosa". DURKHEIM, Emil. "LAS REGLAS DEL MÉTODO SOCIOLÓGICO”. Editorial La Pléyade. Buenos Aires, 1978. Pág. 24.

${ }^{65}$ LIBERMAN, David. "LINGÜÍSTICA, COMUNICACION Y PROCESO PSICOANALÍTICO”. Ediciones Kargieman. Buenos Aires, 1983. Pág. 863.

${ }^{66}$ LIBERMAN, David. "LINGÜÍSTICA, COMUNICACION Y PROCESO PSICOANALÍTICO". Ediciones Kargieman. Buenos Aires, 1983. Pág. 864.

${ }^{67}$ LIBERMAN, David. "LINGÜÍSTICA, COMUNICACION Y PROCESO PSICOANALÍTICO". Ediciones Kargieman. Buenos Aires, 1983. Pág. 870.

${ }^{68}$ HABERMAS, Jürgen. "LALÓGICA DE LAS CIENCIAS SOCIALES”. Editorial Tecnos. Madrid, 1991. Pág. 89.

\section{Un Nuevo Fantasma en la Máquina}

En una nueva situación societal, aún no se sabe bien desde el cognitivismo qué papel asignarle a la conciencia. Con el impacto de la computación esta noción sólo encuentra sentido en la noción de autómata y allí no hay sitio para la conciencia. La razón de las difíciles relaciones entre la mente fenoménica y la computacional es que si hay una mente que decide en conciencia, precisamente en virtud de ella, entonces esa mente no admite una descripción completa como autómata. Las principales dificultades para el conocimiento objetivo de la mente son, por tanto ${ }^{69}$ :

i. la mente fenoménica se enclaustra en una subjetividad de la cual es difícil que salga.

ii. la recuperación del lenguaje mental ha venido sobre todo de la mano de los psicólogos cognitivos, que no se refieren a la mente fenoménica sino a la computacional o, en sentido más amplio, a una mente que funcione sin necesidad de "homúnculos"70 pseudo explicativos.

iii. lo mental se plantea como un complejo mundo de relaciones, donde la descripción mecanicista ya no es completa.

iv. si la mente computacional no es inmediatamente fenoménica, tiene que ser reconstruida de forma muy indirecta, y las inferencias sobre lo mental plantean, en ese caso, un problema de indeterminación.

69 RIVIERE, Angel. “OBJETOS CON MENTE”. Editorial Alianza. Madrid, 1990. Pág. 33.

${ }^{70}$ La idea de homunculus se refiere a la posibilidad de crear un hombre real por medio de algún procedimiento químico. Basado en la existencia de una armonía entre la naturaleza como macrocosmos y el hombre como microcosmos, emerge como la idea de creación de un semejante, como la vieja ambición humana de poner delante a lo otro de sí en su humanidad. Paracelsus, acuñando la idea del homunculus, materializa la esperanza platónica de la armonía universal. Contemporáneo de Lutero, Teofrasto Hohenheim (1493-1541), con su nombre latino Aurelius Bombastus Paracelsus, fue el padre de la idea del homunculus. Por sus descubrimientos fue uno de los precursores de la farmacología moderna. Según su receta, el humunculus "se origina por la digestión de semen humano en el útero de una yegua". Queda abierta la pregunta de si legó en serio esta receta a la posteridad o si sólo quiso dar forma burlesca a su convicción filosófica de la unidad del mundo orgánico. PAPP, Desiderio. "HISTORIA DE LOS AUTÓMATAS. DESDE LA ANTIGÜEDAD HASTA NUESTRA ERA DE LA COMPUTACIÓN". Editorial Compugráfica. Santiago de Chile, 1988. Pág. 32. 


\section{Las Ciencias Cognitivas se Conjugan en Plural}

Ciencias cognitivas es el nombre actual de un conjunto de orientaciones disciplinarias que se conjugan para indicar como horizonte el estudio de la mente ${ }^{71}$. Superando etapas sustantivamen$\mathrm{te}^{72}$, desde hace dos décadas se viene formulando con mayor insistencia la idea de que existen premisas necesarias para el desarrollo de una ciencia cognitiva que incluiría a la Psicología Cognitiva, la Inteligencia Artificial, las Neurociencias, la Lingüística y la Epistemología ${ }^{73}$.

La idea actual de la ciencia cognitiva está indisolublemente ligada a la formación de una sola categoría: mente/máquina. En ella tanto la inteligencia artificial como la psicología cognitiva ocupan puestos centrales en los proyectos. Las diferentes posiciones se refieren nuevamente a los fundamentos de las implicancias de conocimiento y mentelmáquina, por lo que podemos afirmar que estamos en presencia de un hito radical en cuanto a un planteamiento innovador no sólo para la psicología cognitiva sino para un conjunto de ciencias que, por poseer lógicas diversas, se encargan de complejizar el problema del análisis de sus estrategias.

Sin embargo, desde la forma definida en la indagación y las categorías de análisis se puede sostener que aún la relación sujeto/máquina per-

7 VARELA, Francisco y otros. "DE CUERPO PRESENTE”. Editorial Gedisa. Barcelona, 1992. Pág. 29.

${ }^{72}$ Varela de hecho las divide en cuatro etapas:

-la primera con una influencia fundamental de Piaget formulando un programa que replanteaba la epistemología genética, Lorenz describiendo su visión de una epistemología evolutiva y McCulloh comenzando a hablar de una epistemología experimental.

- la segunda etapa donde los símbolos forman parte de la hipótesis cognitivista con la influencia de Chomsky, Minsky y McCarthy haciendo avanzar sustantivamente los resultados vinculándolos a los estadios de la inteligencia artificial.

- la tercera etapa en los primeros años de la cibernética con la predominancia de la lógica como forma de abordaje principal de unas ciencias cognitivas en estado de reconstrucción. Es en esta etapa en que se origina en el cognitivismo la alternativa de la noción de auto-organización.

- la cuarta etapa que se caracteriza por adentrarse en planteamientos de direcciones opuestas conectándolas y pensando los problemas de la resolución de problemas.

VARELA, Francisco. "CONNAITRE: LES SCIENCES COGNITIVES. TENDENCES ET PERSPECTIVES”. Editions Du Seuil. París, 1989.

${ }^{73}$ Colins, 1977; Gardner, 1985; Mandler, 1981; Norman, 1980, Varela, 1990. RIVIERE, Angel. "OBJETOS CON MENTE”. Editorial Alianza. Madrid, 1990. Pág. 109. manece no enteramente iluminada desde la cognición, ya que existen tres rasgos característicos de ella que son contradictorios entre sí:

i. la ciencia cognitiva postularía un nivel de análisis en que el concepto de representación tendría un papel central, un nivel separado del nivel biológico por un lado y el sociológico cultural por otro, donde para la comprensión de la mente el computador sería el modelo más viable.

ii. la tendencia a no considerar las variables emocionales, histórico-culturales.

iii. la interdisciplinariedad y la atención a los problemas espistemológicos planteados por la tradición filosófica de Occidente.

Como podemos ver, existe en esta corriente plural una enorme riqueza potencial de análisis para la relación entre la psicología y la relación sujeto/ máquina. Es necesario superar las contradicciones antes descritas para relevar (poner relevancia) aspectos que si bien no son considerados como fuente de análisis, por ejemplo la dimensión histórica, sí son parte de los supuestos sobre los cuales trabaja, por ejemplo, el computador.

De lo anterior surgen interrogantes que las ciencias cognitivas deben responder, a saber; ¿Cómo es posible usar un modelo de computador para explicar la mente sin considerar los elementos históricos de dicha tecnología si es en el área de la computación donde ha existido una mayor cantidad de transformaciones en menor tiempo? ¿Existe conciencia de que en la metáfora mentelcomputador se acota el concepto de mente a inteligencia artificial, dejando fuera todas las variables emocionales, que la misma I. A. pretende conseguir? ¿Cómo se explica que las ciencias cognitivas recojan la interdisciplinariedad y los supuestos epistemológicos occidentales, siendo esto una opción histórica, y a la vez desconozcan las variables culturales en los análisis acerca de las representaciones?

Estas y otras preguntas son necesarias para que las ciencias cognitivas puedan hacer un mayor aporte a la psicología. Si bien existe un gran avance desde las herencias del conductismo, se requiere un esfuerzo para conectar supuestos epistemológicos con las lógicas teóricas desde las que parten los análisis de esta corriente, ya que una mente $\sin$ contexto es un concepto trunco que guarda, aún, luces y sombras. 


\section{Referencias}

ADORNO, Theodor W. y otros. "LA DISPUTA DEL POSITIVISMO EN LA SOCIOLOGÍA ALEMANA". Editorial Grijalbo. Barcelona, 1973.

BRAUNSTEIN, Néstor. "LA RE-FLEXIÓN DE LOS CONCEPTOS DE FREUD EN LA OBRADE LACAN". Editorial Siglo XXI. México, 1987.

DE LA METTRIE, Julien. "DER MENSCH EINE MASCHINE". Biblioteca Filosófica. Tomo 68. Editorial Dürr. Leipzig.

DURKHEIM, Emil. "LAS REGLAS DEL MÉTODO SOCIOLÓGICO”. Editorial La Pléyade. Buenos Aires, 1978.

ECHEVERRÍA, Rafael. "EL BUHO DE MINERVA". Ediciones PIIE. Santiago de Chile, 1988.

FEYERABEND, Paul. "ADIÓS A LA RAZÓN". Editorial Tecnos. Madrid, 1984.

FOSTER, Hal. "LA POSMODERNIDAD". Editorial Kairós. Barcelona, 1986.

FOUCAULT, Michel. "EL NACIMIENTO DE LA CLÍNICA”. Editorial Siglo XXI. México, 1966.

FOUCAULT, Michel. "LA ARQUEOLOGÍA DEL SABER”. Editorial Siglo XXI. México, 1979.

FOUCAULT, Michel., "LA MICROFÍSICA DEL PODER" Editorial La Piqueta. Madrid, 1979.

FREUD, Sigmund. "LA INTERPRETACIÓN DE LOS SUEÑOS”. Editorial Alianza. Madrid, 1983.

GAUCHET, Marcel. "LE DÉSENCHANTEMENT DU MONDE". Editions Gallimard. París, 1985.

GAUCHET, Marcel. "LA PRODUCCIÓN DEL ORDEN". Ediciones la Piqueta. Madrid, 1990.

HABERMAS, Jürgen. "TEORÍA Y PRAXIS".Editorial Tecnos. Madrid, 1987.

HABERMAS, Jürgen. "LA LÓGICA DE LAS CIENCIAS SOCIALES". Editorial Tecnos. Madrid, 1988.

HEGEL, G. W. F. "FENOMENOLOGÍA DEL ESPÍRITU". Editorial Fondo de Cultura Económica. México, 1966.
HORKHEIMER, Max. "CRITICAL THEORY". The Seabury Press. New York, 1972.

HORKHEIMER, Max. "TEORÍA TRADICIONAL E TEORÍA CRÍTICA". Edição Abril S. A. Cultural, Colección Os Pensadores. São Paulo, 1983.

KUHN, Thomas. "LA TENSIÓN ESENCIAL". Editorial Fondo de Cultura Económica. México, 1987.

LACAN, Jacques. "ESCRITOS”. Editorial Siglo XXI. Buenos Aires, 1977.

LIBERMAN, David. "LINGÜÍSTICA, COMUNICACIÓN Y PROCESO PSICOANALÍTICO". Ediciones Kargieman. Buenos Aires, 1983.

PAPP, Desiderio. "HISTORIA DE LA CIENCIA EN EL SIGLO XX". Editorial Universitaria. Santiago de Chie, 1983.

PAPP, Desiderio. "HISTORIA DE LOS AUTÓMATAS. DESDE LA ANTIGÜEDAD HASTA NUESTRA ERA DE LA COMPUTACIÓN". Editorial Compugráfica. Santiago de Chile, 1988.

PICÓ, Josep. "MODERNIDAD Y POSTMODERNIDAD". Editorial Alianza. Madrid, 1992.

POPPER, Karl. "EL DESARROLLO DEL CONOCIMIENTO CIENTÍFICO. CONJETURAS Y REFUTACIONES". Editorial Paidós. Buenos Aires, 1964.

POPPER, Karl. "LA LÓGICA DE LA INVESTIGACIÓN CIENTÍFICA". Editorial Tecnos. Madrid, 1985.

POPPER, Karl. "CONOCIMIENTO OBJETTVO: UNENFOQUE EVOLUCIONISTA". Editorial Tecnos. Madrid, 1986.

PROUST, Marcel. "EN BUSCA DEL TIEMPO PERDIDO". Ediciones Alianza. Madrid, 1980.

RIVIERE, Angel. "OBJETOS CON MENTE”. Editorial Alianza. Madrid, 1990.

VARELA, Francisco. "CONNAITRE: LES SCIENCES COGNITIVES. TENDENCES ET PERSPECTIVES". Editions Du Seuil. París, 1989.

VARELA, Francisco y otros. "DE CUERPO PRESENTE". Editorial Gedisa. Barcelona, 1992.

WATSON, J.B. "BEHAVIORISM". Chicago Press. Chicago, 1930. 